\title{
Exploring Rapid Photocatalytic Degradation of Organic Pollutants with Porous CuO Nanosheets: Synthesis, Dye Removal, and Kinetic Studies at Room Temperature
}

\author{
Mohammed Nazim,* Aftab Aslam Parwaz Khan, Abdullah M. Asiri, and Jae Hyun Kim*
}

Cite This: ACS Omega 2021, 6, 2601-2612

Read Online

山ll Metrics \& More

回 Article Recommendations

S1 Supporting Information

ABSTRACT: In this work, we report the facile, environmentally friendly, room-temperature (RT) synthesis of porous $\mathrm{CuO}$ nanosheets and their application as a photocatalyst to degrade an organic pollutant/food dye using $\mathrm{NaBH}_{4}$ as the reducing agent in an aqueous medium. Ultrahigh-resolution field effect scanning electron microscopy images of $\mathrm{CuO}$ displayed a broken nanosheet-like (a length of $\sim 160 \mathrm{~nm}$, a width of $\sim 65 \mathrm{~nm}$ ) morphology, and the lattice strain was estimated to be $\sim 1.24 \times 10^{-3}$ using the Williamson-Hall analysis of X-ray diffraction plots. Owing to the strong quantum size confinement effect, $\mathrm{CuO}$ nanosheets resulted in an optical energy band gap of $\sim 1.92 \mathrm{eV}$, measured using Tauc plots of the ultraviolet-visible (UV-vis) spectrum, resulting in excellent photocatalytic efficiency. The RT synthesized $\mathrm{CuO}$ catalyst showed a high Brunauer-Emmet-Teller surface area of $30.88 \pm 0.2313 \mathrm{~m}^{2} / \mathrm{g}(\mathrm{a}$ correlation coefficient of 0.99972 ) with an average Barrett-Joyner-Halenda pore size of $\sim 20.385 \mathrm{~nm}$. The obtained porous $\mathrm{CuO}$ nanosheets exhibited a high crystallinity of $73.5 \%$ with a crystallite size of $\sim 12 \mathrm{~nm}$ and was applied as an efficient photocatalyst for degradation of the

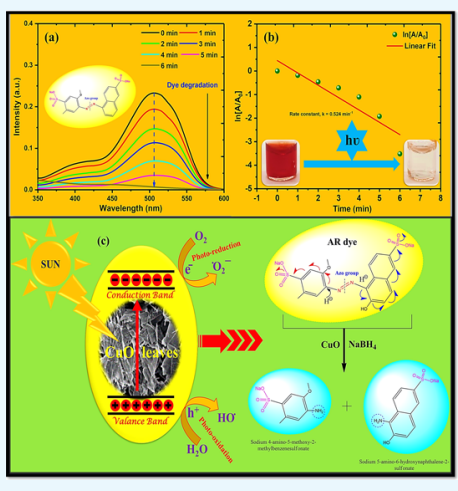
organic pollutant/food dye, Allura Red AC (AR) dye, as monitored by UV-vis spectrophotometric analysis and evidenced by a color change from red to colorless. From UV-vis spectra, CuO nanosheets exhibited an efficient and ultrafast photocatalytic degradation efficiency of $\sim 96.99 \%$ for the AR dye in an aqueous medium within 6 min at RT. According to the Langmuir-Hinshelwood model, photodegradation reaction kinetics followed a pseudo-first-order reaction with a rate constant of $k=0.524 \mathrm{~min}^{-1}$ and a half-life $\left(t_{1 / 2}\right)$ of $2.5 \mathrm{~min}$ for AR dye degradation in the aqueous medium. The $\mathrm{CuO}$ nanosheets showed an outstanding recycling ability for AR degradation and would be highly favorable and an efficient catalyst due to the synergistic effect of high adsorption capability and photodegradation of the food dye.

\section{INTRODUCTION}

Environmental pollution including air, water, and soil pollution is a global issue that seriously endangers the health of this planet's organisms, including human beings. ${ }^{1,2}$ Various efforts have been undertaken to develop efficient, environmentally friendly, and low-cost methods for removing organic dyes/ pollutants from water. ${ }^{3,4}$ Transition-metal oxides are considered to be the most promising catalysts for cleaning wastewater in a facile, reliable, quick, and eco friendly way because of their high photocatalytic activity, excellent solubility, and stability. $\$, 6$ Organic dyes and pigments are considered the most common sources of water pollutants in various sectors, including textile, leather, paper, cosmetics, paint, and printing industries. ${ }^{7,8}$ In particular, textile industrial dye stuffs contain several toxic organic components and are major contributors $(\sim 20 \%)$ to total water pollution among paints, food dyes, food colorants, etc. ${ }^{9,10}$

Organic dyes/pollutants with azo $(-\mathrm{N}=\mathrm{N}-)$ groups and naphthalene or benzene rings account for the largest part $(>50 \%)$ of all industrial organic water pollutants. ${ }^{11,12}$ Various food ingredients make food products more attractive and appealing without any improvement in their nutritional values. ${ }^{13-15}$ Additionally, azo dyes can be reduced to form various amine derivatives which might cause harmful effects and develop a number of health problems, especially in children, such as allergies, immune suppression, urinary problems, and DNA damage. ${ }^{16-18}$ The Allura Red AC (AR) (chemical Formula: $\mathrm{C}_{18} \mathrm{H}_{14} \mathrm{~N}_{2} \mathrm{Na}_{2} \mathrm{O}_{8} \mathrm{~S}_{2}$, molecular weight: 496.4) dye is a synthetic food coloring agent, widely employed in food products, medications, and cosmetics as well as different meat and fish products, chewing gum, soft drinks, jellies and jams, canned food, and various bakery and dairy products. ${ }^{19,20}$

With excess consumption, the AR dye might be harmful to humans and might cause cancer based on World Health Organization (WHO) toxicological data. ${ }^{21-23}$ According to the US Food and Drug Administration (FDA), the AR dye has shown potential toxicity and carcinogenic effects, and it is presently banned in Belgium, Switzerland, France, and Denmark

Received: September 28, 2020

Accepted: December 24, 2020

Published: January 20, 2021 


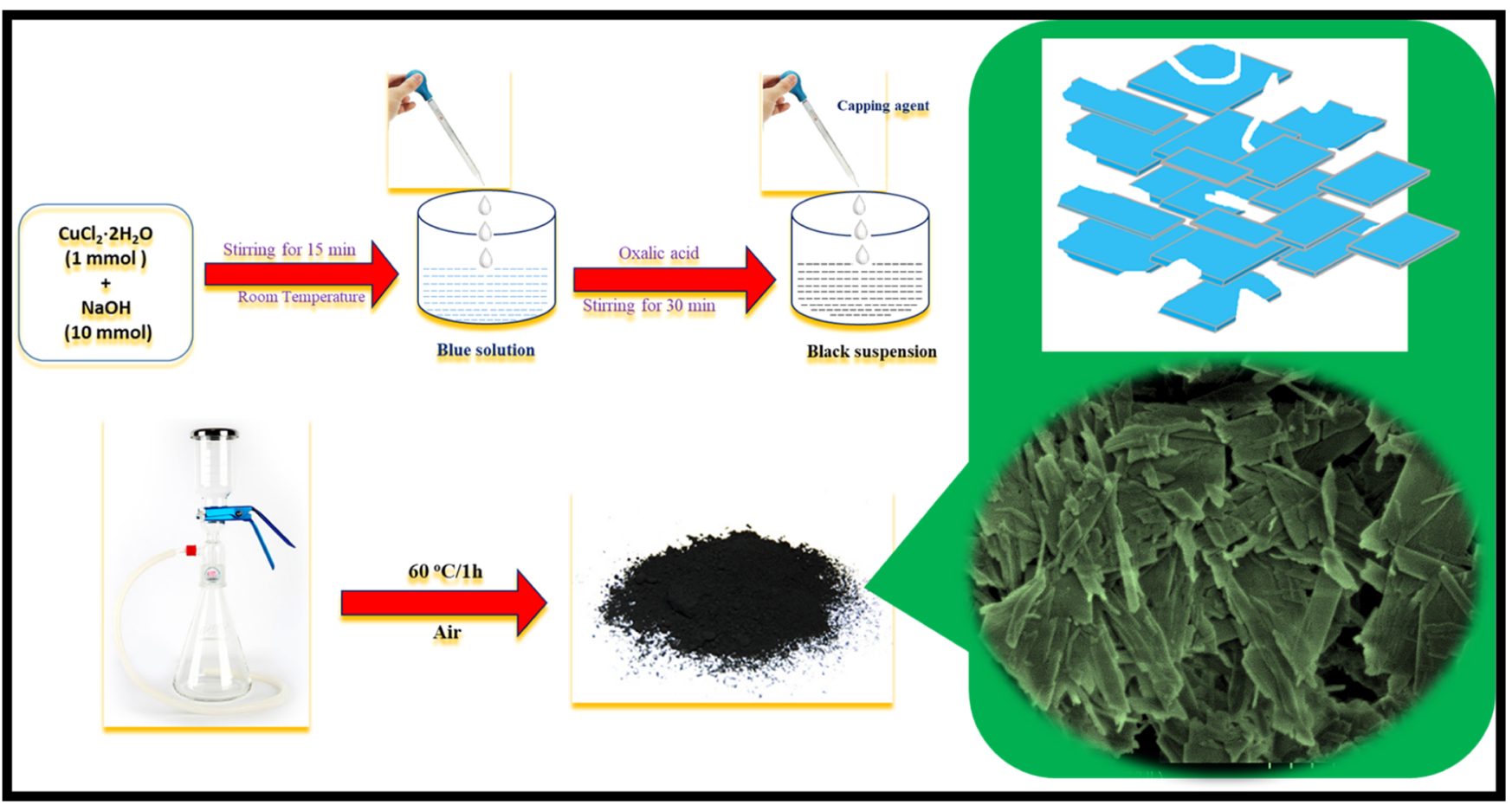

Figure 1. Stepwise synthesis protocol of $\mathrm{CuO}$ nanosheets at RT.

and not recommended for children in the United Kingdom. ${ }^{24}$ Azo dyes exhibit amphoteric properties and explore anionic properties by deprotonation at the acidic group, cationic properties by protonation at the amino group, or non-ionic properties as a function of $\mathrm{pH}$ due to the presence of carboxyl, hydroxyl, amino, or sulfoxyl groups. ${ }^{25}$

Being a p-type semiconductor, cupric oxide $(\mathrm{CuO})$ nanomaterials are considered as highly promising materials for applications in diverse fields including semiconductors, memory devices and field-effect transistors, solar energy, lithium-ion batteries, and photocatalysts for degradation of organic pollutants. ${ }^{26-28}$ Depending on their particular synthetic protocols (Figure 1), $\mathrm{CuO}$ nanomaterials obtain various morphological shapes as nanowires, nanoflowers, nanoplates, nanoboats, and ellipsoid forms, which can greatly influence their photodegradation efficiency toward azo dyes in aqueous media. ${ }^{29,30} \mathrm{CuO}$ nanomaterials possess a monoclinic crystalline structure with a large surface area, high thermal conductivity, high stability, and antimicrobial activity. ${ }^{31} \mathrm{CuO}$ has a monoclinic structure where each $\mathrm{Cu}$ atom contains four nearest neighbor oxygen atoms and exists at the center of the oxygen rectangule, while oxygen atoms are located at the center of a distorted tetrahedron of $\mathrm{Cu}$ atoms. ${ }^{32}$

In this work, we report a facile, room-temperature (RT) synthesis of $\mathrm{CuO}$ broken nanosheets as an efficient photocatalyst for speedy degradation of the organic pollutant/food dye, $\mathrm{AR}$, in aqueous media. The as-prepared $\mathrm{CuO}$ nanosheets were thoroughly characterized by high-resolution powder X-ray diffraction (HR-XRD), X-ray photoelectron spectroscopy (XPS), ultrahigh-resolution scanning electron microscopy (UHR-SEM), high-resolution transmission electron microscopy (HR-TEM), and ultraviolet-visible (UV-vis) absorption spectroscopy. From UV-vis absorption spectra, as-prepared $\mathrm{CuO}$ nanosheets exhibited a strong confinement and size effect, with a high energy band gap, compared to bulk $\mathrm{CuO}$ nanomaterials. The ultrafast catalytic degradation of the AR dye was achieved in an aqueous solution in the presence of $\mathrm{NaBH}_{4}$ as a reducing agent. The as-prepared $\mathrm{CuO}$ broken nanosheets attained $>96 \%$ photodegradation efficiency within 6 min at RT under UV light irradiation.

\section{RESULTS AND DISCUSSION}

Ultrahigh-Resolution Field Effect SEM. To determine the size and morphology of $\mathrm{CuO}$ powder, ultrahigh-resolution field effect SEM (UHR-FESEM) images (Figure 2a,b) with their corresponding elemental mapping images were obtained at different magnifications. The porous morphology of the synthesized $\mathrm{CuO}$ is revealed, composed of torn or broken sheets with different sizes and an average length of $\sim 100-160$ $\mathrm{nm}$, a thickness of $\sim 15 \mathrm{~nm}$, and a width of 25-65 nm. During synthesis, the nanosheet formation process is initiated by the nucleation of nanorods, followed by accumulation or aggregation of multiple $\mathrm{CuO}$ nanorods via self-assembly behavior. $^{33,34}$ The corresponding element mapping images (Figure $2 \mathrm{c}, \mathrm{d}$ ) clearly exhibit the existence of the $\mathrm{Cu}$ and $\mathrm{O}$ elements and the homogeneous dispersion of the $\mathrm{Cu}$ and $\mathrm{O}$ elements throughout the nanosheets. The analyses of the $\mathrm{CuO}$ nanosheet length and width are shown in the histogram profile (Figure 2e,f) with standard deviation analysis.

High-Resolution Transmission Electron Microscopy. The TEM image (Figure $2 \mathrm{~g}$ ) of $\mathrm{CuO}$ exhibits various types of $\mathrm{CuO}$ nanosheets, which resemble broken nanosheets of about $>100 \mathrm{~nm}$ lengths. From lattice fringes, $\mathrm{CuO}$ nanosheets have a highly crystalline broken sheetlike morphology, and the $d$ spacing of crystallographic planes was calculated using fast Fourier transform (FFT) patterns to be $\sim 0.45 \mathrm{~nm}$, which is consistent with (111) crystal planes of monoclinic-phase $\mathrm{CuO}$ nanomaterials. ${ }^{35}$ The typical TEM images of as-prepared $\mathrm{CuO}$ nanostructures demonstrate a broken sheetlike morphology and support surface structure observed by UHR-FESEM analysis.

Energy-Dispersive X-Ray Spectroscopy. The elemental composition and phase purity of $\mathrm{CuO}$ nanosheets were further 

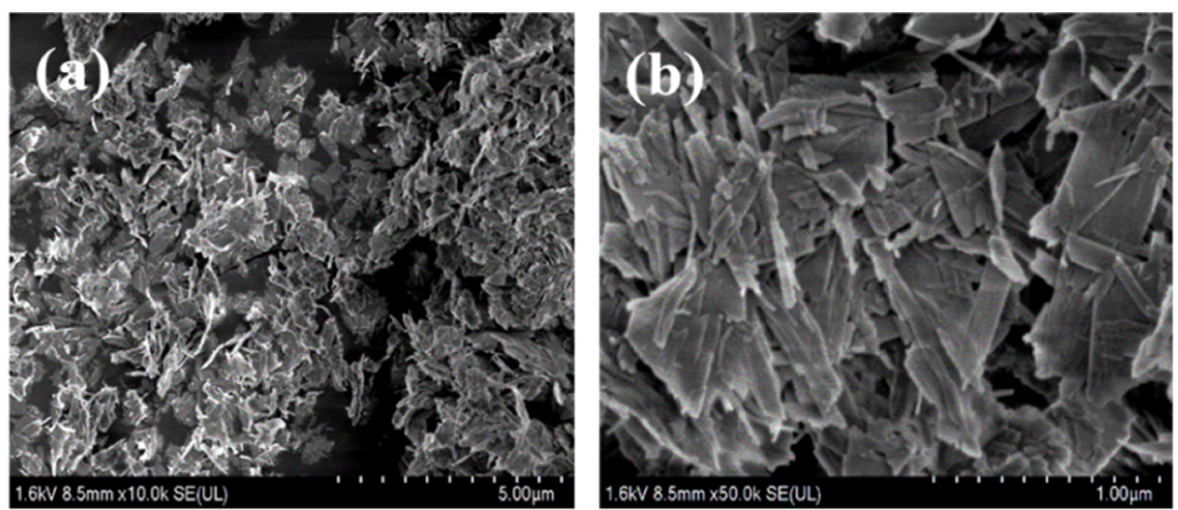

\section{Cu L $\alpha 1,2$}
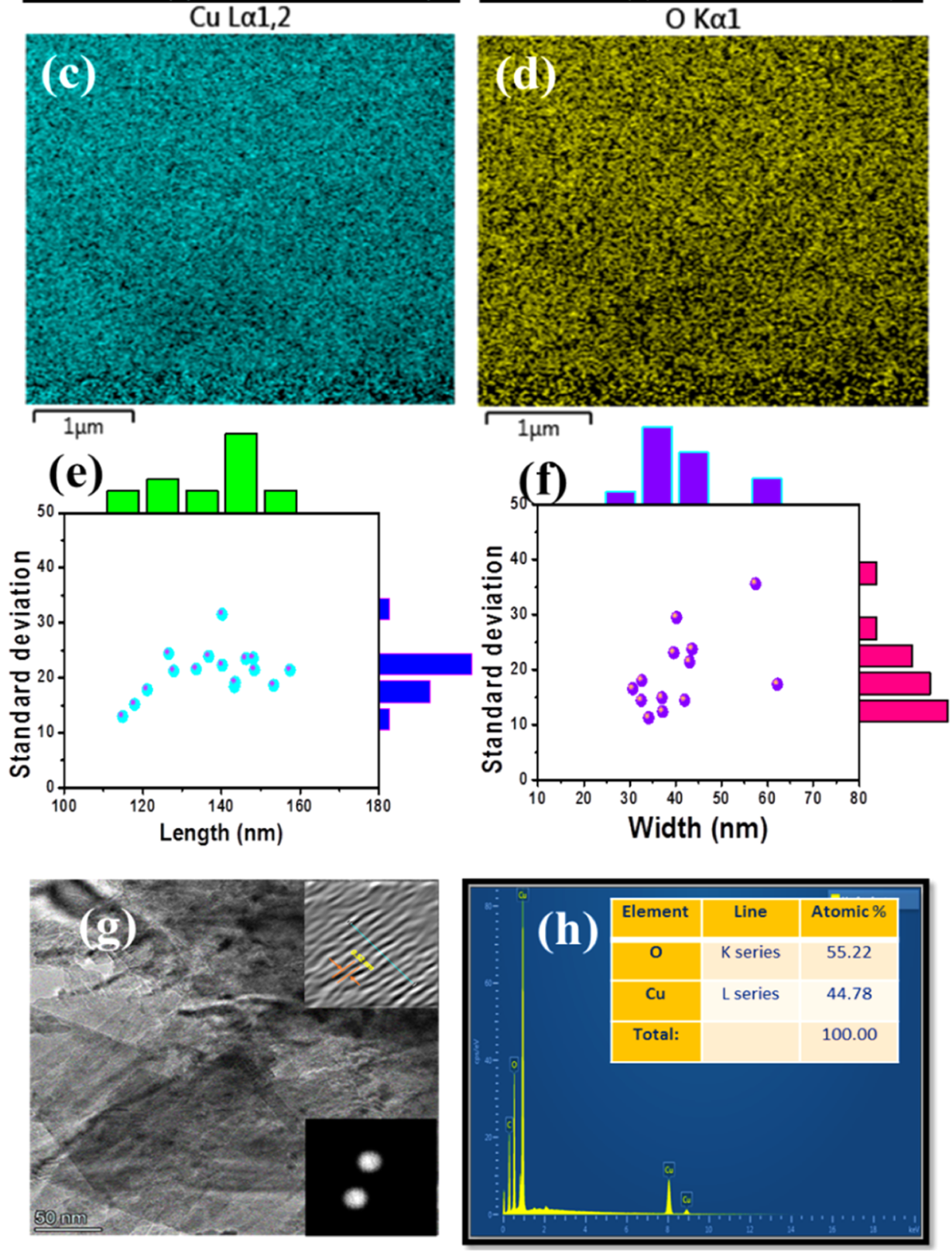

Figure 2. UHR-FESEM images of $\mathrm{CuO}$ nanosheets; (a) low-magnification and (b) high-magnification images with elemental mapping of (c) Cu element and (d) $\mathrm{O}$ element. (e) $\mathrm{CuO}$ nanosheet width histogram profile with standard deviation. (f) $\mathrm{CuO}$ nanosheet length histogram profile with standard deviation. (g) HR-TEM image of $\mathrm{CuO}$ broken nanosheets with FFT patterns. (h) EDX spectral (inset: atomic percentage of elements) plot of $\mathrm{CuO}$ nanosheets.

analyzed by energy-dispersive X-ray (EDX) analysis. The EDX spectra (Figure $2 \mathrm{~h}$ ) of $\mathrm{CuO}$ nanosheets showed the presence of only $\mathrm{Cu}$ and $\mathrm{O}$ as major components at a molecular ratio of $\mathrm{Cu} /$ $\mathrm{O}(1: 1)$, which is in agreement with the stoichiometric 

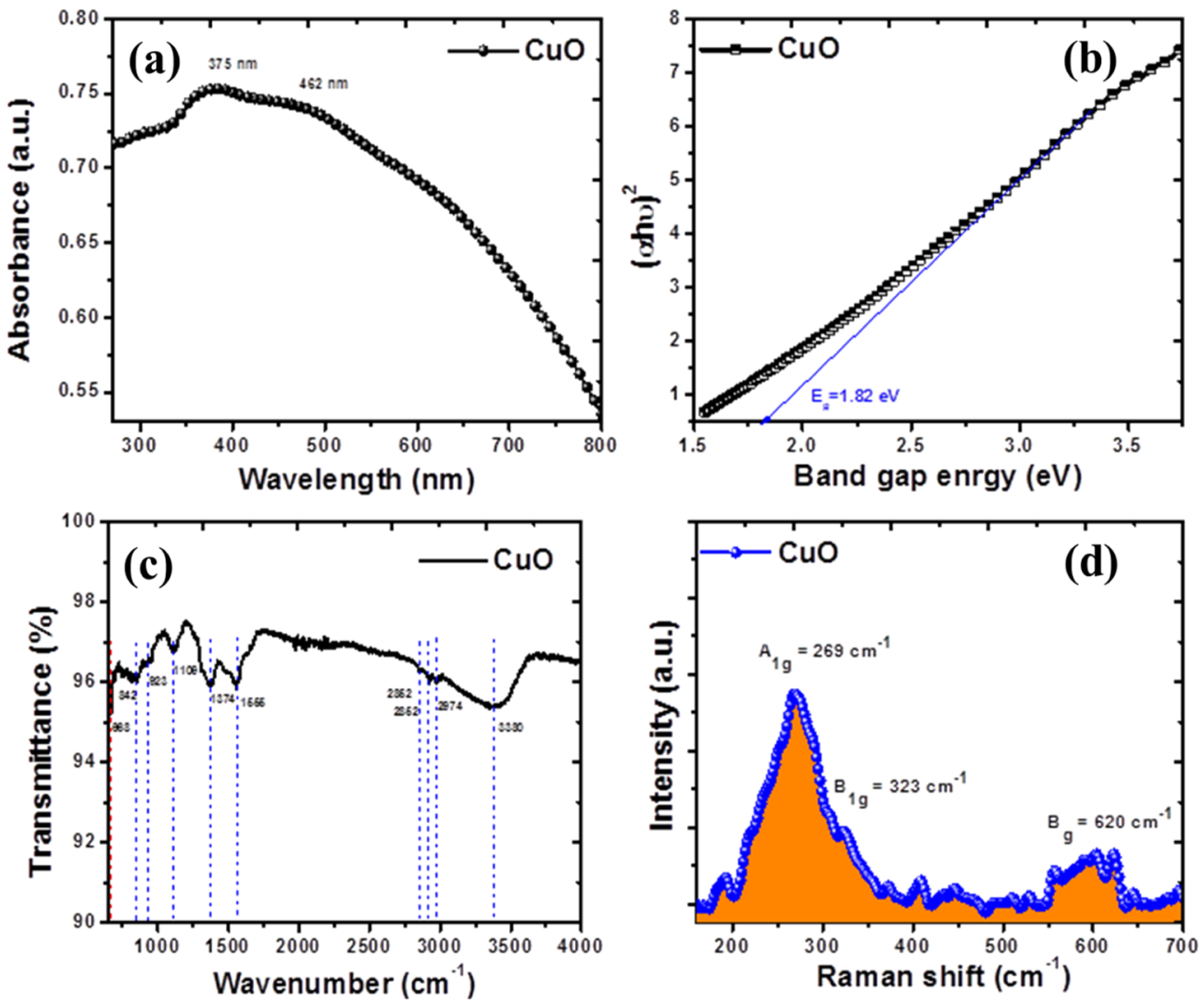

Figure 3. (a) UV-vis spectrum and (b) corresponding Tauc plot of $\mathrm{CuO}$ nanosheets; (c) FT-IR spectrum; (d) FT-Raman spectrum of RT synthesized $\mathrm{CuO}$ nanosheets.

proportion of $\mathrm{CuO}$ in the $\mathrm{Cu}^{2+}$ oxidation state. Furthermore, the $\mathrm{CuO}$ nanosheet powder also contains some carbon byproducts from the organic precursor along with the main $\mathrm{Cu}$ and $\mathrm{O}$ elements. ${ }^{36}$

Optical Properties of Porous CuO Nanosheets. In photocatalysis, the optical band gap of the transition-metal oxide plays a very significant role in determining light harvesting ability. In UV-vis spectral (Figure 3) plots, $\mathrm{CuO}$ nanosheets have shown two peaks at $\sim 375$ and $\sim 462 \mathrm{~nm}$. In general, reduction in nanoparticle size improves not only the band gap but also the surface area of $\mathrm{CuO}$ nanosheets, leading to more efficient photodegradation performance.

Lowering the size of nanomaterials leads to a small charge diffusion length, which minimizes the charge-recombination process due to rapid charge transfer, resulting in improved photocatalytic efficiency (PE). ${ }^{37}$ The optical energy band gap of $\mathrm{RT}$ synthesized $\mathrm{CuO}$ nanosheets was estimated by the Tauc plot (Figure $3 \mathrm{~b}$ ), where the $(\alpha h \nu)^{2}$ versus $h \nu$ plot can be used in following equation

$$
\left(\alpha E_{\text {photon }}\right)^{2}=K\left(E_{\text {photon }}-E_{\mathrm{g}}\right)
$$

where $\alpha$ is the absorption coefficient, $E_{\text {photon }}=h \nu$ is the photon energy, $K$ is a constant, and $E_{\mathrm{g}}$ is the optical energy band gap. The estimated optical energy band gap $\left(E_{\mathrm{g}}=1240 / \lambda_{\text {edge }}\right)$ of $\mathrm{CuO}$ broken nanosheets was about $\sim 1.92 \mathrm{eV}$, which is much larger than that of bulk $\mathrm{CuO}(\sim 1.20 \mathrm{eV})$ crystals. $^{38}$ The high band gap of RT synthesized $\mathrm{CuO}$ nanosheets is attributed to quantum size confinement effects which result from the nanosized morphology of metal oxide semiconducting materials resulting in size-dependent optical properties.
Fourier Transform Infrared Spectroscopy. The Fourier transform infrared (FT-IR) spectra (Figure 3c) of $\mathrm{CuO}$ nanosheets show a broad and high frequency band at 3382 $\mathrm{cm}^{-1}$, corresponding to the hydroxyl $(\mathrm{OH})$ functional group of the capping agent applied during synthesis. Along with this, three characteristic alkane $\mathrm{C}-\mathrm{H}$ stretching bands appeared at 2974,2852 , and $2783 \mathrm{~cm}^{-1}$. Additionally, broad IR frequency bands in the range of $\sim 1300$ to $\sim 4000 \mathrm{~cm}^{-1}$ are assigned to chemisorbed and/or physisorbed $\mathrm{H}_{2} \mathrm{O}$ and $\mathrm{CO}_{2}$ molecules on the surface of $\mathrm{CuO}$ nanosheets. In the IR spectrum, the sharp band at $\sim 1374 \mathrm{~cm}^{-1}$ is assigned to the $\mathrm{C}-\mathrm{H}$ deformation vibration of alkanes, along with a strong band at $\sim 1555 \mathrm{~cm}^{-1}$ corresponding to $\mathrm{C}=\mathrm{O}$ stretching vibrations of carboxylic groups. ${ }^{39}$ The band at $\sim 1109 \mathrm{~cm}^{-1}$ is assigned to the $\mathrm{C}-\mathrm{O}-\mathrm{C}$ antisymmetric stretching vibration band of carboxylic acid groups of oxalates. The IR bands in the frequency range of $\sim 1000$ to $700 \mathrm{~cm}^{-1}$ in the fingerprint region are attributed to the $\mathrm{C}-\mathrm{O}$ stretching and in-plane $\mathrm{C}-\mathrm{H}$ bending vibrations. Furthermore, the peak at $\sim 923 \mathrm{~cm}^{-1}$ is assigned to the bending vibration of the $\mathrm{C}-\mathrm{H}$ group, and the frequency band of $\sim 842$ $\mathrm{cm}^{-1}$ is attributed to the bending vibrations of $\mathrm{O}-\mathrm{M}-\mathrm{O}$ bonds. However, the characteristic peak at a low frequency of $\sim 668$ $\mathrm{cm}^{-1}$ corresponds to the typical $\mathrm{Cu}-\mathrm{O}$ stretching vibration band. ${ }^{40}$

Fourier Transform Raman Spectroscopy. Raman spectroscopy is a very useful tool for monitoring the structural disorder and crystalline nature of various metal oxide materials at RT. FT-Raman spectroscopy provided further evidence of the monoclinic crystal phase (Figure 3d) of $\mathrm{CuO}$ nanosheets. FTRaman spectral plots exhibited three strong peaks at 270, 335, and $597 \mathrm{~cm}^{-1}$, which were assigned to the monoclinic 

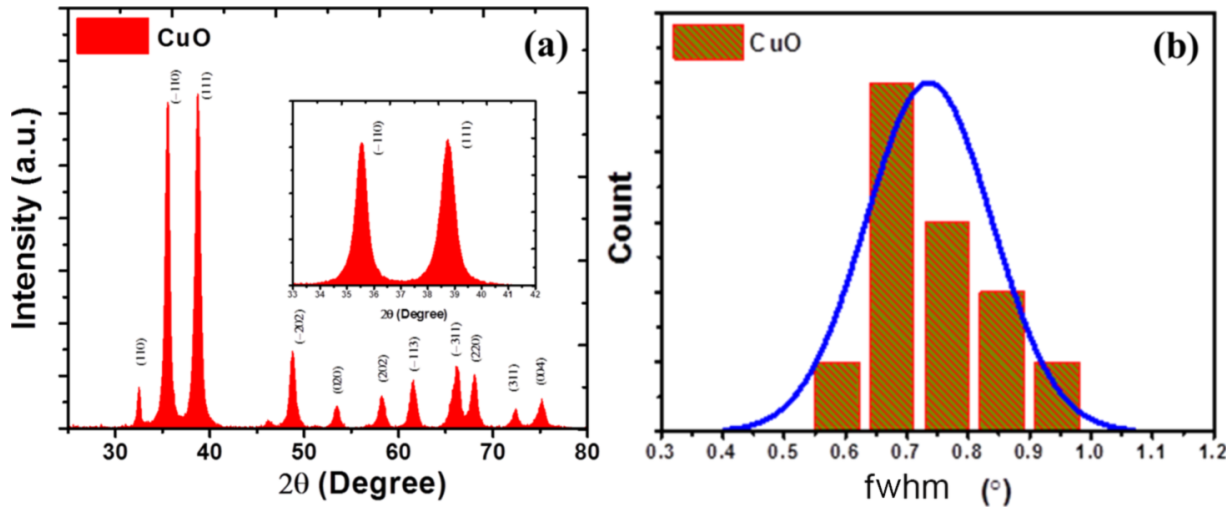

Figure 4. (a) Powder XRD spectrum and (b) histogram profile of fwhm of RT synthesized $\mathrm{CuO}$ nanosheets.

orientation of $\mathrm{A}_{1 \mathrm{~g}}, \mathrm{~B}_{1 \mathrm{~g}}$, and $\mathrm{B}_{\mathrm{g}}$ vibrational modes of $\mathrm{CuO}$ nanosheets, respectively. ${ }^{41}$ From the Raman spectrum, a peak around $\sim 100 \mathrm{~cm}^{-1}$ might have appeared due to Raman scattering at the edge due to vibrations induced by disorder or by an impurity that became Raman-active owing to breakage of selection rules. Crystal lattice imperfections and oxygen deficiencies resulting from the impurity might broaden Raman peaks as the grain size of metal-oxide nanomaterials decreases. The broadened peaks of XRD and Raman spectra indicate a small size of $\mathrm{CuO}$ nanoparticles which agglomerate to form porous $\mathrm{CuO}$ nanosheets. ${ }^{42}$

Powder X-ray Diffraction Spectroscopy. Powder XRD (Figure 4) was applied as a precise and efficient tool to investigate the crystalline phase and size of $\mathrm{CuO}$ nanostructures. The diffraction peaks of $\mathrm{CuO}$ nanosheets were at Bragg angle $(2 \theta)$ values of $32.536,35.584,38.768,48.813,53.453,58.243$, $61.566,66.143,68.074,72.451$, and $75.222^{\circ}$, which belong to the crystal plane indices of the (110), $(002) /(-111),(111)$, (-202), (020), (202), (-113), (-311), (220), (311), and $(-222)$ phases, respectively. The XRD peaks reveal a monoclinic crystalline phase $\left(\alpha=\gamma=90^{\circ}\right.$ and $\left.\beta=99.5^{\circ}\right)$ of $\mathrm{CuO}$ (space group $C_{12} / C_{1}$, JCPDS no. 98-008-7124) with lattice constants of $a=4.687, b=3.422$, and $c=5.130 \AA$ at RT. The $\mathrm{XRD}$ results indicate that as-obtained $\mathrm{CuO}$ nanosheets are composed of a pure monoclinic crystal phase with a full width at half-maximum (fwhm) value of $0.74 \mathrm{~nm}$, obtained by using Gaussian fit curves. ${ }^{43}$ Additionally, the degree of crystallinity (Table 1) indicates positions of various atoms or molecular

Table 1. Structural Parameters of RT Synthesized $\mathrm{CuO}$ Nanosheets

\begin{tabular}{cccccc} 
material & $\begin{array}{c}\text { wavelength } \\
(\mathrm{nm})\end{array}$ & $\begin{array}{c}\text { energy } \\
\text { band gap } \\
(\mathrm{eV})\end{array}$ & $\begin{array}{c}\text { crystallite } \\
\text { size }(\mathrm{nm})\end{array}$ & $\begin{array}{c}\text { fwhm } \\
(\mathrm{deg})\end{array}$ & strain $(\varepsilon)$ \\
$\begin{array}{c}\mathrm{CuO} \\
\text { nanosheets }\end{array}$ & 375,462 & 1.92 & 12 & 0.72 & $1.24 \times 10^{-3}$ \\
\hline
\end{tabular}

arrangements in powder materials, which can be calculated using the following relation

$$
\begin{aligned}
& \text { Crystallinity }(\%) \\
& =\frac{\text { total area of crystalline peaks }}{\text { total area of all (crystalline and amorphous) peaks }} \\
& \quad \times 100
\end{aligned}
$$

The RT synthesized $\mathrm{CuO}$ nanosheets exhibited $~ 73.5 \%$ crystallinity, suggesting the high crystalline nature of the $\mathrm{CuO}$ photocatalyst which is beneficial to rapid dye degradation.

From XRD plots, the crystal orientation of $\mathrm{CuO}$ and the crystallite grain size of $\mathrm{CuO}$ nanosheets were calculated using the Debye-Scherrer formula

$$
D=K \lambda / \beta \cos \theta
$$

where $D$ is the crystallite size, $K$ is the shape factor (0.9), $\lambda$ is the $\mathrm{X}$-ray wavelength, $\beta$ is the fwhm, and $\theta$ is the Bragg angle of the XRD peak. The average crystallite size $\left(D_{\text {average }}\right)$ of $\mathrm{CuO}$ nanosheets was estimated to be $\sim 12 \mathrm{~nm}$ (Table 1) for degradation of the organic pollutant at RT.

Among solid nanomaterials, XRD peak broadening might be attributed to the presence of an impurity in the crystal lattice, which creates defects infinitely in all the directions. The fwhm value (Figure $4 \mathrm{~b}$ ) was estimated to be 0.72 for $\mathrm{CuO}$ broken nanosheets. The Williamson-Hall $(\mathrm{W}-\mathrm{H})$ analysis suggests the XRD peak-width relation with the XRD intensity of $2 \theta$ peak positions for calculating the lattice strain, according to the equation

$$
\beta \cos \theta=(k \lambda / D)+4 \varepsilon \sin \theta
$$

where $\varepsilon$ is the lattice strain, $D$ is the particle size, $\beta$ is the peak broadening at the fwhm value of the $\mathrm{CuO}$ powder, $\lambda$ is the $\mathrm{X}$-ray wavelength, $k$ is a constant, and $\theta$ is Braggs angle. From the $\mathrm{W}-$ $\mathrm{H}$ plot (Figure $\mathrm{S} 1$ ), the calculated strain of $\mathrm{CuO}$ nanosheets was found to be $1.24 \times 10^{-3}$ at RT.

X-ray Photoelectron Spectroscopy. The chemical constituents of $\mathrm{CuO}$ nanosheets with their oxidation states were analyzed by XPS spectral plots. For $\mathrm{CuO}$, XPS spectra (Figure 5) were used to investigate transition-metal compounds with localized valence d-orbitals, and copper metal ${ }_{29} \mathrm{Cu}$ in the $\mathrm{d}^{9} \mathrm{~s}^{2}$ configuration) exists mainly in the divalent oxidation state $\left(\mathrm{Cu}^{2+}\right.$ ion) with the $\mathrm{d}^{9}$ configuration. The $\mathrm{Cu} 2 \mathrm{p}$ spectrum (Figure 5a) displays two sharp and distinctive peaks of $\mathrm{Cu} 2 \mathrm{p}_{3 / 2}$ and $\mathrm{Cu} 2 \mathrm{p}_{1 / 2}$ oxidation states, with their corresponding strong shake-up satellite peaks, indicating the coexistence of two forms of $\mathrm{Cu}^{2+}$ ions in nonequivalent chemical environments. ${ }^{44}$

The $\mathrm{Cu} 2 \mathrm{p}_{3 / 2}$ peak was situated at 933.80 with its asymmetric satellite shoulder peaks at 941.00 and $943.80 \mathrm{eV}$, corresponding to the $\mathrm{Cu}^{2+}$ oxidation state of $\mathrm{CuO}$ nanosheets. In addition, the satellite peak at $943.80 \mathrm{eV}$ provides an evident proof of the $\mathrm{d}^{9}$ shell of the $\mathrm{Cu}^{2+}$ state, which is a characteristic of copper oxide materials with a $\mathrm{d}^{9}$ configuration in the ground state. ${ }^{45}$ Additionally, the $\mathrm{Cu} 2 \mathrm{p}_{1 / 2}$ peak of $\mathrm{CuO}$ was situated at 953.67 $\mathrm{eV}$ with the corresponding shake-up satellite peak at $962.33 \mathrm{eV}$, 

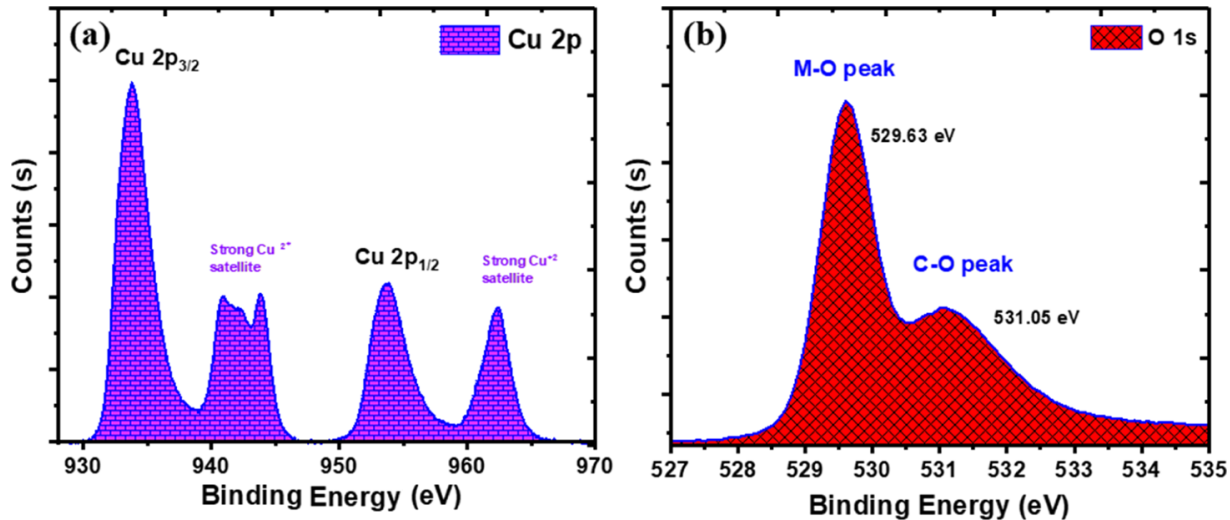

Figure 5. X-ray photoelectron spectral plots of (a) $\mathrm{Cu} 2 \mathrm{p}$ and (b) O 1s elements for RT synthesized CuO nanosheets.

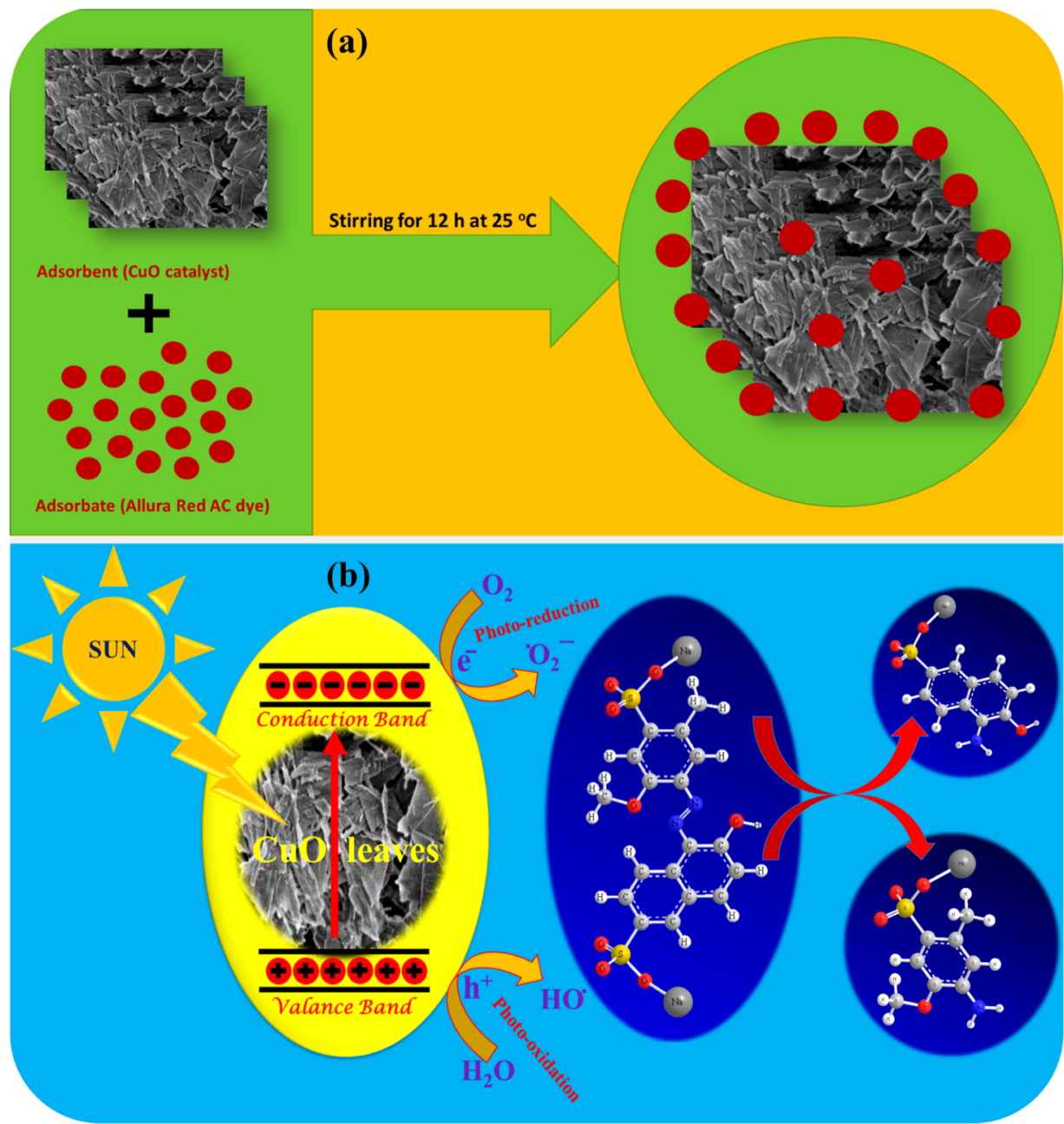

Figure 6. Proposed model presentation of the AR dye degradation mechanism by RT synthesized CuO nanosheets; (a) adsorption of the dye on CuO nanosheets and (b) catalytic degradation of the AR dye in the presence of light.

indicating the $\mathrm{Cu}^{2+}$ ionic state in pure $\mathrm{CuO}$. The difference in binding energy between two characteristic peaks was calculated from spectra to be $\sim 20.13 \mathrm{eV}$ of the $\mathrm{Cu}$ spectrum. ${ }^{46}$

The $\mathrm{O} 1 \mathrm{~s}$ spectra (Figure $5 \mathrm{~b}$ ) of $\mathrm{CuO}$ nanosheets display asymmetric peaks suggesting different chemical environments and at least two oxygen species of oxide ions. The strong peak at a binding energy of $529.63 \mathrm{eV}$ is attributed to $\mathrm{O}^{2-}$ ions bonded to $\mathrm{Cu}^{2+}$ ions in the monoclinic crystal system. The additional broad peak at $531.05 \mathrm{eV}$ might belong to vacant oxygen sites and the surface-chemisorbed oxygen peak as $\mathrm{H}_{2} \mathrm{O}$ or $\mathrm{O}_{2}$ from the environment, resulting in weakly bonded oxygen species with $\mathrm{CuO}$ nanosheets. ${ }^{47}$ The $\mathrm{C} 1$ s profiles (Figure S2) of $\mathrm{CuO}$ displayed a robust peak at $284.62 \mathrm{eV}$, indicating an $\mathrm{sp}^{2}$ hybridized $\mathrm{C}-\mathrm{C}$ carbon bond with a shoulder peak at $286.15 \mathrm{eV}$ belonging to the $\mathrm{C}-\mathrm{O}$ bond. Additionally, peaks at $287.98 \mathrm{eV}$ are assigned to $\mathrm{O}-\mathrm{C}=\mathrm{O}$ or $\mathrm{COOH}$ groups, introduced by utilization of oxalic acid as a capping agent during the synthesis of the $\mathrm{CuO}$ catalyst. $^{48}$ 

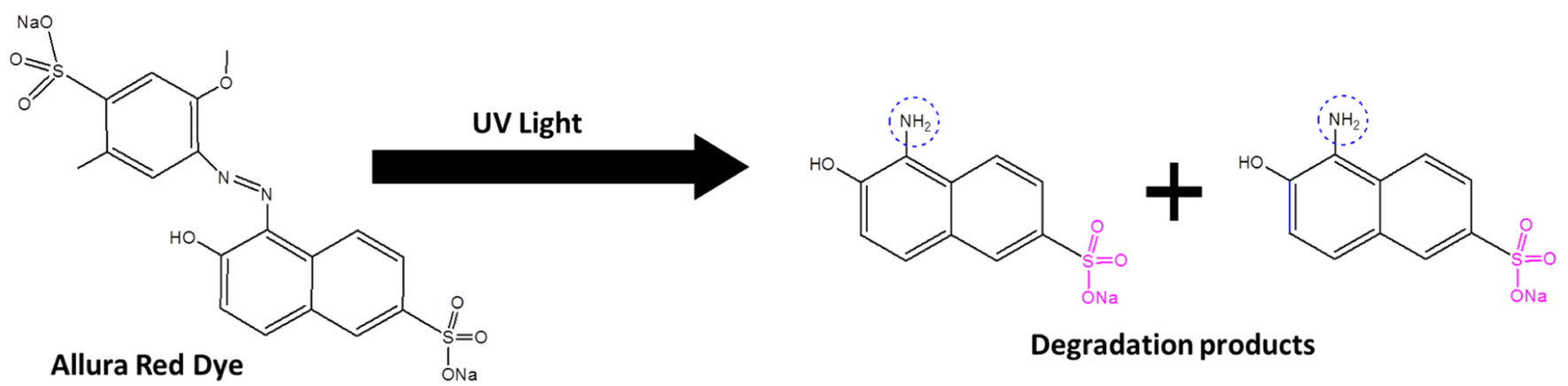

Figure 7. Degradation products of the AR dye in the presence of the $\mathrm{CuO}$ catalyst.

Brunauer-Emmet-Teller Surface Analysis of Porous CuO Nanosheets. It has been investigated that the obtained surface area of the $\mathrm{CuO}$ nanosheet catalyst is very high compared to the surface area of the commercial $\mathrm{CuO}$ powder (ca. $0.1 \mathrm{~m}^{2} / \mathrm{g}$ ) which revels a highly porous surface morphology and provides a large area to adsorb dye molecules, resulting in efficient and superfast degradation of the dye. ${ }^{49}$ From Brunauer-Emmet-Teller (BET) investigation (Figure S3), RT grown $\mathrm{CuO}$ nanosheets exhibit a high surface area of $\sim 30.88$ $\pm 0.2313 \mathrm{~m}^{2} / \mathrm{g}$, with an average pore size of $\sim 20.385 \mathrm{~nm}$ and an average pore volume of $0.146 \mathrm{~cm}^{3} / \mathrm{g}$. The highly porous structure of $\mathrm{CuO}$ nanosheets provides a bigger surface to facilitates mass transport during photodegradation reaction in aqueous solution. The porous $\mathrm{CuO}$ nanosheets have good crystalline nature and a clean surface without any bonding or adsorbing of surfactant molecules. However, in this work, $\mathrm{CuO}$ nanosheets provide a high surface area of $\sim 30 \mathrm{~nm}$ compared to the previous report. ${ }^{50}$ Using the Barret-Joyner-Halenda (BJH) method, the values of pore volume and pore size show a highly mesoporous character of $\mathrm{CuO}$ nanosheets. ${ }^{51}$ Specifically, the $\mathrm{CuO}$ catalyst displays a $\mathrm{BJH}$ adsorption average pore size (Figure S3 inset) of $\sim 19.37 \mathrm{~nm}$ and a desorption average pore size of $\sim 21.39 \mathrm{~nm}$. For $\mathrm{CuO}$ nanosheets, the $\mathrm{BJH}$ adsorption and desorption pore volumes were estimated as $\sim 0.14113$ and $\sim 0.15088 \mathrm{~cm}^{3} / \mathrm{g}$, respectively.

Proposed Mechanism of Photocatalytic Degradation of the Organic Pollutant/Dye Solutions. Owing to their complex aromatic structures, organic pollutants/dyes are very stable in aqueous solutions, which is a big concern for environmental water pollution. To remove organic pollutants, a tentative reaction mechanism (Figure 6) is proposed, which involves $\mathrm{OH}$ free radicals as active oxidizing agents during the photocatalytic process. During light-driven catalytic degradation, the band position of the catalyst determines the strength of the oxidation or reduction process. The catalyst nanomaterials are excited by light irradiation and form electron-hole pairs $\left(\mathrm{e}^{-} / \mathrm{h}^{+}\right.$pairs called excitons $)$which interact with hydride radicals (of the $\mathrm{NaBH}_{4}$ reducing agent) to create a reactive oxygen species known as a superoxide $\left(\mathrm{O}_{2}{ }^{-}\right)$ion and hydroxyl free radicals. ${ }^{52}$ The oxygen-containing radicals $\left(\mathrm{O}_{2}{ }^{-\bullet}\right.$ and $\left.\mathrm{HO}^{\bullet}\right)$ might react with electrons and holes to produce more hydroxyl radicals $\left(\bullet^{\bullet} \mathrm{OH}\right)$, which derive photodegradation efficiency and enable ultrafast degradation of the AR dye under UV-vis light irradiation. The degradation process produces amine derivatives (colorless) which finally decompose to produce $\mathrm{CO}_{2}$ and water.

To evaluate the effect of dye adsorption (Figure 6a) on the catalyst surface, the $\mathrm{CuO}$ catalyst was dissolved in the $\mathrm{AR}$ aqueous solution and stirred for $12 \mathrm{~h}$ at RT. When a freshly prepared aqueous solution of $\mathrm{NaBH}_{4}$ was added to the AR solution in the absence of the $\mathrm{CuO}$ catalyst, no visible color change could be observed. Nevertheless, maximum absorption peak centered at $\sim 506 \mathrm{~nm}$ remained unaltered even after excessive addition of the $\mathrm{NaBH}_{4}$ solution, which proved no degradation of the AR dye in the absence of the catalyst. At the chemical structural point, the presence of various functional groups in the AR dye can significantly affect photodegradation performance and yield of reaction.

The chromophore groups and azo bonds $(-\mathrm{N}=\mathrm{N}-)$ in dyes are responsible for the red color and display a strong peak at a $\sim 506 \mathrm{~nm}$ wavelength due to $\mathrm{n} \rightarrow \pi^{*}$ transition which is susceptible to photocatalytic degradation under UV light. At $t=$ 0 min, UV absorption spectra of the AR solution with and without the $\mathrm{CuO}$ catalyst were recorded at RT. The degradation started with the addition of the $\mathrm{NaBH}_{4}$ solution in terms of intensity decrease at RT. Hence, AR dye degradation (Figure 6b) might follow a possible breakage of the azo bond as the chromophoric group, which causes decolorization of the dye solution via the following steps

$$
\begin{aligned}
& \text { AR Dye }+\mathrm{CuO} \rightarrow[\text { Dye-CuO]adsorbed product }+h \nu \\
& \rightarrow[\text { Dye-CuO }]^{*} \\
& {[\text { Dye-CuO }]^{*} \rightarrow \mathrm{CuO}\left[\mathrm{h}^{+}+\mathrm{e}^{-}\right](\text {exciton }) \rightarrow \text { dye }+\mathrm{h}^{+}} \\
& \rightarrow \text { dye* } \\
& \mathrm{H}_{2} \mathrm{O}+\mathrm{h}^{+} \rightarrow \mathrm{OH}^{\bullet}(\text { hydroxyl radical })+\mathrm{H}^{+} \\
& \mathrm{NaBH}_{4} \rightarrow \mathrm{Na}^{+}+\mathrm{BH}_{4}^{-} \\
& \mathrm{BH}_{4}^{-} \rightarrow \mathrm{BH}_{3}+\mathrm{H}^{+}+\mathrm{e}^{-} \text {(electron) } \\
& \mathrm{O}_{2}+\mathrm{e}^{-} \rightarrow \mathrm{O}_{2}^{-}+\mathrm{H}_{2} \mathrm{O} \\
& \rightarrow \mathrm{OH}^{\bullet}(\text { hydroxyl radical })+\mathrm{OH}^{-} \\
& \text {Dye* }+\mathrm{OH}^{\bullet} \rightarrow \text { degradation products }+\mathrm{CO}_{2}+\mathrm{H}_{2} \mathrm{O}
\end{aligned}
$$

During AR dye degradation, the $\mathrm{CuO}$ nanosheets displayed efficient catalytic activity with $\mathrm{NaBH}_{4}$ as the reducing agent in aqueous solution. The process was monitored by UV-vis spectrophotometry at RT. The sodium borohydride $\left(\mathrm{NaBH}_{4}\right)$ reducing agent acts as a hydride ion source (to produce electrons), while $\mathrm{CuO}$ catalysts activate the azo bond of the AR dye via conjugation. Additionally, ultrafast dye degradation with $\mathrm{CuO}$ nanosheets might be due to additional electrons generated by $\mathrm{BH}_{4}{ }^{-}$and efficient charge transfer by the $\mathrm{CuO}$ catalyst toward the AR dye. 

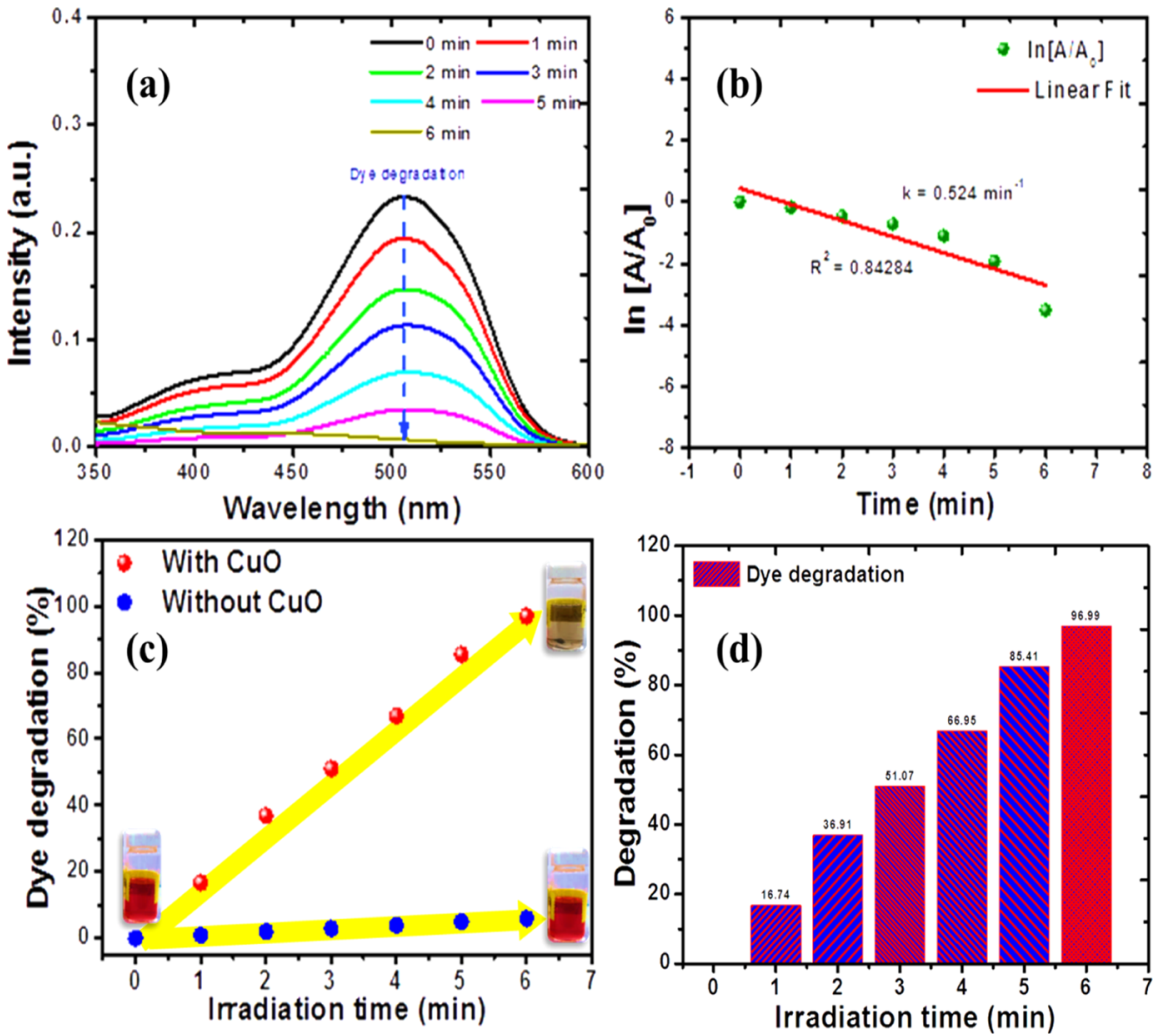

Figure 8. (a) UV-vis spectral plots of dye degradation at different time intervals and (b) corresponding reaction rate kinetic plot; (c) degradation percentage vs time curves of the $\mathrm{AR}$ dye with and without the $\mathrm{CuO}$ catalyst; $(\mathrm{d})$ gradual degradation histogram profile against time of the AR dye in the aqueous medium.

The photodegradation reaction of the $\mathrm{AR}$ dye by $\mathrm{CuO}$ nanosheets was investigated using UV-vis absorption spectroscopy as gradual dye discoloration (lowering absorbance), measured as a function of time using Beer-Lambert's law. The AR dye gives degradation products (Figure 7) as amine derivatives (general formula, $\mathrm{C}_{8} \mathrm{H}_{10} \mathrm{NSNaO}_{4}$, mol. wt: 239.22, and $\mathrm{C}_{10} \mathrm{H}_{8} \mathrm{NSNaO}_{4}$, mol. wt: 261.23 ) which finally degrade into water and carbon dioxide on further photodegradation.

Catalytic Degradation of the AR Dye in the Aqueous Medium. The organic dye pollutant, namely, the AR dye, was chosen to investigate catalytic activity of $\mathrm{CuO}$ broken nanosheets under sunlight. To monitor the photocatalytic study of $\mathrm{CuO}$ nanostructures, $5 \mathrm{mg}$ of prepared $\mathrm{CuO}$ nanostructures was dispersed in deionized water $(10 \mathrm{~mL})$ by sonication for $30 \mathrm{~min}$. The AR dye solution $(1 \mathrm{mg} / 10 \mathrm{~mL})$ was added separately into the $\mathrm{CuO}$ dispersed solution and stirred for $12 \mathrm{~h}$ at RT to attain an adsorption-desorption equilibrium of $\mathrm{CuO}$ and the AR dye. The photocatalytic degradation reaction (Figure 8) of the organic pollutant started with the addition of the $\mathrm{NaBH}_{4}(1 \mathrm{mg} / \mathrm{mL})$ solution as a reducing agent. In the absence of $\mathrm{CuO}$ nanostructures, the absorption peak intensity remained the same after the addition of the reducing agent, $\mathrm{NaBH}_{4}$. On light exposure, the main absorbance peak at $\sim 506$ $\mathrm{nm}$ from the azo groups in the AR dye gradually decreases, which can be evaluated to determine the PE (Table 2) of $\mathrm{CuO}$ nanosheets. The absorption peak intensity remains the same after the addition of the reducing agent, $\mathrm{NaBH}_{4}$, in the absence of $\mathrm{CuO}$ nanostructures. Due to the large kinetic barrier, the rate of dye photodegradation is extremely slow and negligible in the absence of the $\mathrm{CuO}$ nanocatalyst besides a thermodynamically favorable reaction. ${ }^{53}$ After a specific time interval, a $2 \mathrm{~mL}$ sample
Table 2. Photocatalytic Efficiency and Reaction Kinetic Parameters of the AR Dye Solution

$\begin{array}{ccccc}\text { dye } & \begin{array}{c}\text { rate constant } \\ \left(\mathrm{k}, \mathrm{min}^{-1}\right)\end{array} & \begin{array}{c}\text { half-life }\left(t_{1 / 2}\right) \\ (\mathrm{min})\end{array} & \mathrm{PE}(\%) & \begin{array}{c}\text { degradation time } \\ (\mathrm{min})\end{array} \\ \text { AR dye } & 0.524 & 2.5 & 96.99 & 6\end{array}$

solution was collected and centrifuged to remove the catalyst and then analyzed using UV-vis spectroscopy. The removal of the organic pollutants/dye (Figure S4) was apparent and confirmed by conversion of the dye solution (red color) to a degraded dye (colorless solution). Due to the strong quantum size confinement effect, $\mathrm{CuO}$ nanosheets exhibited high band gap energy, high crystallinity, and eminent photocatalytic activity for instant photodegradation of organic pollutants. ${ }^{54}$

\section{CATALYTIC EFFICIENCY OF POROUS CUO NANOSHEETS AS A PHOTOCATALYST}

The possible mechanism of excellent catalytic performance of $\mathrm{RT}$ synthesized $\mathrm{CuO}$ nanosheets is attributed to high adsorption ability toward AR via the high BET surface area and high porosity along with the large pore size compared to commercial $\mathrm{CuO}$ powder. Owing to high nucleophilicity, $\mathrm{BH}_{4}^{-}$anions supply more electrons to enhance dye degradation reaction. ${ }^{55}$ In addition, high dispersing ability of the $\mathrm{CuO}$ catalyst in water also results in highly efficient contact between $\mathrm{CuO}$ nanosheets and the AR dye. The enhanced $\mathrm{PE}$ of $\mathrm{CuO}$ might be due to shift in light absorption toward the visible range, resulting in an increase of optical band gap. During photocatalytic degradation, oxygen sites appeared on $\mathrm{CuO}$ nanosheets which reduce $\mathrm{O}_{2}$ and form superoxide radicals, resulting in the ultrafast photocatalytic degradation of the organic pollutants in the aqueous medium. 
The photocatalytic degradation efficiency (Figure 8a) of RT synthesized $\mathrm{CuO}$ nanosheets as a catalyst was observed with absorbance variation at the maximum wavelength $\left(\lambda_{\max }\right)$ peak of the AR dye at different time intervals. The AR dye solution exhibited the highest-intensity absorption peak at $\sim 506 \mathrm{~nm}$, along with two low-intensity peaks at $\sim 315$ and $\sim 405 \mathrm{~nm}$ in water. According to the Beer-Lambert law, the $\mathrm{PE}$ of $\mathrm{CuO}$ nanosheets can be calculated using following equation

$$
\text { Photocatalytic efficiency }(\%)=\left(1-A_{t} / A_{0}\right) \times 100
$$

where $A_{0}$ represents the absorbance of the AR dye aqueous solution at time $t=0$ and $A_{t}$ is the absorbance of the dye aqueous solution after time $t$ of photoirradiation. Due to the addition of the $\mathrm{CuO}$ nanocatalyst, the absorption intensity of the azo dye declines with cleavage of azo bonds, producing colorless amino derivatives. On UV light irradiation, the AR dye was efficiently degraded by the $\mathrm{CuO}$ nanosheet photocatalyst and a PE of $\sim 96.99 \%$ (Table 2) was evaluated in 6 min at RT. Additionally, ultrafast decolorization of the dye was evidenced by disappearance of the maximum intensity peak at $506 \mathrm{~nm}$ wavelength. The superfast organic pollutant/dye degradation was attributed to superior electron-transfer ability and the effective light harvesting tendency of $\mathrm{CuO}$ nanosheets. ${ }^{56}$

\section{REACTION KINETICS OF PHOTOCATALYTIC DEGRADATION OF THE ORGANIC POLLUTANT/AR DYE}

Generally, a large redox potential barrier between the electrondonor $\left(\mathrm{BH}_{4}^{-}\right)$ion and electron acceptor (dyes) kinetically suppresses rapid degradation of the AR dye in aqueous solution. RT synthesized $\mathrm{CuO}$ nanosheets might improve electron transfer owing to the large surface for dye adsorption via an electrostatic attraction to boost desirable photodegradation reactions within a few minutes.

In addition, the presence of excess $\mathrm{NaBH}_{4}$ during photodegradation reactions establishes a pseudo-first-order kinetic mechanism using the Langmuir-Hinshelwood model (Figure $8 \mathrm{~b}$ ) for AR dye degradation. ${ }^{57}$ Due to the linear relation of AR dye degradation, the photodegradation rate constant, $k$, can be calculated as follows

$$
\ln \left(A_{t} / A_{0}\right)=-k t
$$

where $k$ is the pseudo-first-order rate constant and $A_{t}$ and $A_{0}$ are the corresponding absorbance values of the AR dye solution at time $t$ and $0 \mathrm{~min}$, respectively. During the photocatalytic process, the absorbance change $\left(A_{t} / A_{0}\right)$ of the AR solution appears to be directly proportional to concentration change $\left(C_{t} / C_{0}\right)$ which can be derived from the Beer-Lambert law. In this work, the linear fit curve of $\ln \left(A / A_{0}\right)$ versus time $(t, \min )$ plots (Figure $8 \mathrm{~b}$ ) established that degradation of AR undergoes a pseudo-firstorder reaction kinetics.

When RT synthesized $\mathrm{CuO}$ nanosheets were used as a photocatalyst, the rate constant $(\mathrm{k})$ of the photodegradation reaction of the AR dye was calculated to be $0.524 \mathrm{~min}^{-1}$. The high $\mathrm{PE}$ of $\mathrm{CuO}$ can be attributed to the high band gap and the porous sheetlike morphology, which enhances dye adsorption capacity. Additionally, the half-life $\left(t_{1 / 2}\right)$ of the degradation reactions (Figure $8 \mathrm{c}, \mathrm{d}$ ) was also estimated in the presence and absence of the $\mathrm{CuO}$ photocatalyst in terms of $(\ln 2) / k$ relation. The photodegradation of the dye with $\mathrm{CuO}$ nanosheets exhibited a low value of $t_{1 / 2}(\sim 2.5 \mathrm{~min})$, revealing the strong $\mathrm{PE}$ of $\mathrm{CuO}$ nanosheets compared to the high $t_{1 / 2}$ value of 36.6 min (Table 2) for photodegradation reaction without the $\mathrm{CuO}$ catalyst. $^{58}$

Reusability of the CuO Catalyst. The reusability and recovery of the catalyst $\mathrm{CuO}$ after the photocatalytic experiment are crucial and important features during research. The $\mathrm{CuO}$ catalyst could be readily separated from the reaction mixture and makes it possible to reuse $\mathrm{CuO}$ nanosheets. From Figure S5, $\mathrm{CuO}$ catalysts retained their original catalytic activity even after 10 cycles, which indicates good stability $(>90 \%)$ of the $\mathrm{CuO}$ catalyst. ${ }^{59}$ Furthermore, the $\mathrm{CuO}$ catalyst was recovered from the reaction mixture at the end of each process, washed with water and ethanol, dried in a vacuum oven, and then characterized for XRD (Figure S6a) and FESEM images (Figure S6b) for storage to apply in next degradation cycles at ambient temperature. From Figure S5, $\mathrm{CuO}$ catalysts retained their original catalytic activity even after 10 cycles, which indicates good stability $(>90 \%)$ of the $\mathrm{CuO}$ catalyst. ${ }^{60}$ Therefore, good catalytic efficiency, good stability, and facile recycling ability of $\mathrm{RT}$ synthesized $\mathrm{CuO}$ made the catalyst promising for environmental remediation.

\section{CONCLUSIONS}

In summary, we have demonstrated the facile, environmentally friendly RT synthesis of porous $\mathrm{CuO}$ broken nanosheets and applied them as catalysts to degrade the organic pollutant/food dye, the AR dye using $\mathrm{NaBH}_{4}$ as a reducing agent in aqueous solution. The UHR-FESEM images revealed a broken nanosheet-like morphology (a length up to $\sim 160 \mathrm{~nm}$, a width up to $\sim 65 \mathrm{~nm}$ ). The strain of $\mathrm{CuO}$ nanosheets was estimated to be $\sim 1.24 \times 10^{-3}$ using Williamson-Hall analysis from XRD spectra. The $\mathrm{CuO}$ nanosheets exhibited a high optical energy band gap of $\sim 1.92 \mathrm{eV}$ due to the strong quantum size confinement effect, as determined by using Tauc plots. The Raman spectral plots exhibited three strong peaks at 270, 335, and $597 \mathrm{~cm}^{-1}$, which were assigned to the monoclinic orientation of the $\mathrm{A}_{1 \mathrm{~g}}, \mathrm{~B}_{1 \mathrm{~g}}$, and $\mathrm{B}_{\mathrm{g}}$ vibrational modes of $\mathrm{CuO}$ nanosheets, respectively. From XRD plots, the obtained $\mathrm{CuO}$ nanosheets exhibited a high crystallinity of $73.5 \%$ with a crystallite size of $\sim 12 \mathrm{~nm}$. The RT synthesized $\mathrm{CuO}$ catalyst showed a high BET surface area of $30.88 \pm 0.2313 \mathrm{~m}^{2} / \mathrm{g}$ (a correlation coefficient of 0.9997268 ) with an average BJH pore size of $\sim 20.385 \mathrm{~nm}$. From UV-vis spectra, the PE of RT synthesized $\mathrm{CuO}$ nanosheets exhibited an efficient and ultrafast dye degradation of $\sim 96.99 \%$ for the AR dye in $6 \mathrm{~min}$. According to the Langmuir-Hinshelwood model, dye degradation reaction kinetics followed a pseudo-first-order reaction, with a rate constant of $k=0.524 \mathrm{~min}^{-1}$, with a half-life $\left(t_{1 / 2}\right)$ of $2.5 \mathrm{~min}$ for $\mathrm{AR}$ dye degradation reaction.

\section{EXPERIMENTAL SECTION}

Materials and Methods. All the abovementioned chemicals were of analytical grade and were used without any further purification. Copper chloride dihydrate $\left(\mathrm{CuCl}_{2} \cdot 2 \mathrm{H}_{2} \mathrm{O}\right)$, sodium hydroxide $(\mathrm{NaOH})$, and oxalic acid dihydrate were all purchased from Sigma-Aldrich, Korea. During experiments, deionized water was used to make up aqueous solutions of various components.

Characterizations. UHR-FESEM images of $\mathrm{CuO}$ nanosheets were obtained with a Hitachi (SU 8230) instrument using fine powder, along with their elemental mapping images. EDX was employed to evaluate the weight percent of various elements. During degradation, UV-vis spectra of the AR dye 
(quartz cuvette) solutions were recorded using a Cary 5000 UV-vis-NIR spectrophotometer (Agilent Technologies) with D2 and tungsten lamps in the range of 200-800 nm wavelengths. At RT, UV absorption spectra were calibrated against deionized water as the background in the same quartz cuvette. HR-XRD spectra were recorded in the range of $5-80^{\circ}$ with $\mathrm{Cu} \mathrm{K} \alpha$ radiation $(\lambda=1.5406 \AA$ ) using an X-ray diffractometer (Empyrean, Panalytical, USA) to analyze structural properties of the $\mathrm{CuO}$ nanosheet powder. The elemental composition of $\mathrm{CuO}$ nanosheets was measured using X-ray photoelectron spectroscopic analysis in an ultrahigh vacuum setup equipped with a monochromatic $\mathrm{Al} \mathrm{K} \alpha \mathrm{X}$-ray source $(1486.6 \mathrm{eV})$ (ESCALAB 250Xi, Thermo Fisher Scientific, USA) at RT. HR-TEM (S-4800, Hitachi, Japan) was employed to examine the atomic structure and various lattice planes of the $\mathrm{CuO}$ powder, and the lattice $d$-spacing value was calculated by FFT patterns of TEM images. FT-IR spectroscopy (Nicolet Continuum, Thermo Fisher Scientific, USA) was performed in the attenuated total reflectance mode at a resolution of $4 \mathrm{~cm}^{-1}$. FT-IR spectra of $\mathrm{CuO}$ were recorded in range of $4000-650 \mathrm{~cm}^{-1}$ at RT. Raman spectroscopy was performed using a confocal Raman spectrometer (Thermo Fisher Scientific, Nicolet Almeca XRA) with a $\lambda_{\text {ex }}$ of $532 \mathrm{~nm}$ at $\mathrm{RT}$. The photocatalytic activity of $\mathrm{CuO}$ for degradation of the AR dye was evaluated at ambient temperature using a UV-visNIR spectrophotometer.

RT Synthesis of CuO Nanosheets. At RT, copper chloride dihydrate $\left(\mathrm{CuCl}_{2} \cdot 2 \mathrm{H}_{2} \mathrm{O}, 2 \mathrm{mmol}\right)$ and sodium hydroxide $(\mathrm{NaOH}, 20 \mathrm{mmol})$ were dissolved (1:10 molar ratio) in 50 $\mathrm{mL}$ of deionized water (Figure 1) and stirred for $15 \mathrm{~min}$ to get a homogeneous blue-colored solution. The reaction progress was monitored through naked eyes, and the reaction mixture changed from blue green to blue. Then, oxalic acid dihydrate ( $4 \mathrm{mmol}$ ) was added as a capping agent slowly in the reaction mixture with constant stirring at RT. The reaction mixture was stirred for $30 \mathrm{~min}$ and converted into a black suspension. Furthermore, $\mathrm{Cu}^{2+}$ ions can react with $\mathrm{OH}^{-}$ions to produce a $\mathrm{Cu}(\mathrm{OH})_{2}$ precipitate. ${ }^{60}$ However, excess $\mathrm{OH}^{-}$ions react with copper ions to form a blue solution of $\left[\mathrm{Cu}(\mathrm{OH})_{4}\right]^{2-}$ complex ions which convert into $\mathrm{CuO}$ as follows

$$
\begin{aligned}
& \left.\mathrm{CuCl}_{2} \cdot 2 \mathrm{H}_{2} \mathrm{O} \text { [blue-green color }\right]+2 \mathrm{OH}^{-} \\
& \left.\quad \rightarrow \mathrm{Cu}(\mathrm{OH})_{2} \text { [precipitate }\right] \\
& \left.\mathrm{Cu}(\mathrm{OH})_{2}+2 \mathrm{OH}^{-} \rightarrow\left[\mathrm{Cu}(\mathrm{OH})_{4}\right]^{2-} \text { [blue color }\right] \\
& \left.\left[\mathrm{Cu}(\mathrm{OH})_{4}\right]^{2-} \rightarrow \mathrm{CuO} \text { [black color }\right]+\mathrm{H}_{2} \mathrm{O}
\end{aligned}
$$

The synthesized $\mathrm{CuO}$ nanosheets were separated by centrifugation at $6000 \mathrm{rpm}$ for $10 \mathrm{~min}$ at RT. The reaction mixture was filtered and thoroughly washed with ethanol and deionized water several times. The raw solid powder was then dried at $60{ }^{\circ} \mathrm{C}$ for $1 \mathrm{~h}$ to get pure $\mathrm{CuO}$ nanosheets as a black powder.

Catalytic Experiments. The organic food dye, namely, AR, was chosen to investigate catalytic activity of RT grown $\mathrm{CuO}$ nanosheets at RT. For degradation reaction, $10 \mathrm{~mL}$ of the aqueous solution of the dye $\left(5 \mathrm{mg} \mathrm{L}^{-1}\right)$ was added with a freshly prepared $\mathrm{NaBH}_{4}(1 \mathrm{mg} / \mathrm{mL})$ solution to record the peak intensity under UV-visible spectra. Immediately, the preferred amount of catalyst was added to precede degradation reaction which can be observed by color change of the solution from red to colorless with stirring solution. The supernatant was then transferred to a quartz cuvette for the UV-vis spectral measurement. After the UV spectrum was recorded, the solution was transferred back to the previous reaction vessel while stirring. The process was repeated and UV-visible spectra were recorded consecutively to check the progress of the reaction. In addition, blank experiments were also conducted to confirm that reactions did not proceed with the catalyst in the absence of $\mathrm{NaBH}_{4}$ or without the catalyst in the presence of $\mathrm{NaBH}_{4}$. The influence of catalyst amount and reusability of the $\mathrm{CuO}$ catalyst were investigated for degradation reaction. To test reusability, 10 consecutive cycles of the catalyst were carried out with a fixed amount of the catalyst. In consecutive cycles, the catalyst was recovered by centrifugation, followed by washing with distilled water three times, and characterized by XRD and FESEM of $\mathrm{CuO}$ nanosheets. Further, the recovered catalyst was employed against the fresh reaction mixture, as described previously.

\section{ASSOCIATED CONTENT}

\section{Supporting Information}

The Supporting Information is available free of charge at https://pubs.acs.org/doi/10.1021/acsomega.0c04747.

Williamson-Hall plots, XPS plots, BET surface area plots, reusability plots of 10 cycles, and XRD and FESEM images of $\mathrm{CuO}$ nanosheets after 10 degradation cycles of the AR dye (PDF)

\section{AUTHOR INFORMATION}

\section{Corresponding Authors}

Mohammed Nazim - Division of Energy Technology, Daegu Gyeongbuk Institute of Science \& Technology (DGIST), Daegu 42988, Republic of Korea; 이이이.org/0000-0002-33912677; Email: nazimopv@gmail.com

Jae Hyun Kim - Division of Energy Technology, Daegu Gyeongbuk Institute of Science \& Technology (DGIST), Daegu 42988, Republic of Korea; (1) orcid.org/0000-0003-28240113; Email: jaehyun@dgist.ac.kr

\section{Authors}

Aftab Aslam Parwaz Khan - Chemistry Department, Faculty of Science, King Abdulaziz University, Jeddah 21589, Saudi Arabia; 이이이.org/0000-0002-3746-5034

Abdullah M. Asiri - Chemistry Department, Faculty of Science and Center of Excellence for Advanced Materials Research, King Abdulaziz University, Jeddah 21589, Saudi Arabia

Complete contact information is available at:

https://pubs.acs.org/10.1021/acsomega.0c04747

\section{Notes}

The authors declare no competing financial interest.

\section{ACKNOWLEDGMENTS}

This project was funded by the Deanship of Scientific Research (DSR) under research grant (Project Grant No. G-554-1301441) at King Abdulaziz University, Jeddah, Saudi Arabia. The authors therefore, acknowledge with thanks DSR for technical and financial suppot. This research was also supported by the Daegu Gyeongbuk Institute of Science and Technology R\&D Program (20-ET-08) of the Ministry of Science and ICT of Korea. 


\section{REFERENCES}

(1) Ren, Z. J.; Umble, A. K. Water treatment: Recover wastewater resources locally. Nature 2016, 529, 316-325.

(2) Sha, Y.; Mathew, I.; Cui, Q.; Clay, M.; Gao, F.; Zhang, X. J.; Gu, Z. Rapid degradation of azo dye methyl orange using hollow cobalt nanoparticles. Chemosphere 2016, 144, 1530-1535.

(3) Li, W.-W.; Yu, H.-Q.; Rittmann, B. E. Chemistry: Reuse water pollutants. Nature 2015, 528, 29-31.

(4) dos Santos, A. B.; Cervantes, F. J.; van Lier, J. B. Review paper on current technologies for decolourisation of textile wastewaters: Perspectives for anaerobic biotechnology. Bioresour. Technol. 2007, 98, 2369-2385.

(5) Lasio, B.; Malfatti, L.; Innocenzi, P. Photodegradation of Rhodamine 6G dimers in silica sol-gel films. J. Photochem. Photobiol., A 2013, 271, 93-98.

(6) Buthiyappan, A.; Abdul Aziz, A. R.; Wan Daud, W. M. A.; Daud, W. Recent advances and prospects of catalytic advanced oxidation process in treating textile effluents. Rev. Chem. Eng. 2016, 32, 1-47.

(7) Arslan, I.; Balcioğlu, I. A. Degradation of commercial reactive dyestuffs by heterogenous and homogenous advanced oxidation processes: a comparative study. Dyes Pigment 1999, 43, 95-108.

(8) Cooper, P. Removing color from dye house waste waters-A critical review of technology available. J. Soc. Dyers Color. 1993, 109, 97-100.

(9) Pagga, U.; Taeger, K. Development of a method for adsorption of dyestuffs on activated sludge. Water Res. 1994, 28, 1051-1057.

(10) Forgacs, E.; Cserháti, T.; Oros, G. Removal of synthetic dyes from wastewaters: a review. Environ. Int. 2004, 30, 953-971.

(11) Wongrakpanich, A.; Mudunkotuwa, I. A.; Geary, S. M.; Morris, A. S.; Mapuskar, K. A.; Spitz, D. R.; Grassian, V. H.; Salem, A. K. Sizedependent cytotoxicity of copper oxide nanoparticles in lung epithelial cells. Environ. Sci.: Nano 2016, 3, 365-374.

(12) Salem, M. A.; Al-Ghonemiy, A. F.; Zaki, A. B. Photocatalytic degradation of Allura red and Quinoline yellow with polyaniline $/ \mathrm{TiO}_{2}$ nanocomposite. Appl. Catal., B 2009, 91, 59-66.

(13) Wang, Y.; Wang, D.; Yan, B.; Chen, Y.; Song, C. Fabrication of diverse $\mathrm{CuO}$ nanostructures via hydrothermal method and their photocatalytic properties. J. Mater. Sci.: Mater. Electron. 2016, 27, 6918-6924.

(14) Saadati, F.; Khani, N.; Rahmani, M.; Piri, F. Preparation and characterization of nanosized copper (II) oxide embedded in hypercross-linked polystyrene: highly efficient catalyst for aqueous-phase oxidation of aldehydes to carboxylic acids. Catal. Commun. 2016, 79, 26-30.

(15) Wang, Y.; Jiang, T.; Meng, D.; Yang, J.; Li, Y.; Ma, Q.; Han, J. Fabrication of nanostructured $\mathrm{CuO}$ films by electrodeposition and their photocatalytic properties. Appl. Surf. Sci. 2014, 317, 414-421.

(16) Andrews, B.; Almahdali, S.; James, K.; Ly, S.; Crowder, K. N. Copper oxide surfaces modified by alkylphosphonic acids with terminal pyridyl-based ligands as a platform for supported catalysis. Polyhedron 2016, 114, 360-369.

(17) Shu, H.-Y.; Chang, M.-C.; Yu, H.-H.; Chen, W.-H. Reduction of an azo dye Acid Black 24 solution using synthesized nanoscale zerovalent iron particles. J. Colloid Interface Sci. 2007, 314, 89-97.

(18) Chani, M. T. S.; Karimov, K. S.; Khan, S. B.; Asiri, A. M. Fabrication and investigation of cellulose acetate-copper oxide nanocomposite based humidity sensors. Sens. Actuators, A 2016, 246, 58-65.

(19) Wu, D.; Yan, J.; Wang, J.; Wang, Q.; Li, H. Characterisation of interaction between food colourant allura red $\mathrm{AC}$ and human serum albumin: Multispectroscopic analyses and docking simulations. Food Chem. 2015, 170, 423-429.

(20) Tsuda, S.; Murakami, M.; Matsusaka, N.; Kano, K.; Taniguchi, K.; Sasaki, Y. F. DNA damage induced by red food dyes orally administered to pregnant and male mice. Toxicol. Sci. 2001, 61, 92-99.

(21) Zhong, Y.; Shi, T.; Liu, Z.; Cheng, S.; Huang, Y.; Tao, X.; Liao, G.; Tang, Z. Ultrasensitive non-enzymatic glucose sensors based on different copper oxide nanostructures by in-situ growth. Sens. Actuators, B 2016, 236, 326-333.
(22) Amchova, P.; Kotolova, H.; Ruda-Kucerova, J. Health safety issues of synthetic food colorants. Regul. Toxicol. Pharmacol. 2015, 73, 914-922.

(23) Li, K.; Lu, J.; Zheng, X.; Lian, Q. Three-dimensional hierarchical superstructures of $\mathrm{CuO}$ nanoflowers: Facile synthesis and applications for enhanced photocatalytic activity of dyes. Russian J. Appl. Chem. 2019, 92, 71-77.

(24) Honma, M. Evaluation of the in vivo genotoxicity of Allura red AC (Food Red No. 40). Food Chem. Toxicol. 2015, 84, 270-275.

(25) Tang, W. Z.; Huren An, H. UV/ $/ \mathrm{TiO}_{2}$ photocatalytic oxidation of commercial dyes in aqueous solutions. Chemosphere 1995, 31, 41574170.

(26) Wang, H.; Pan, Q.; Zhao, J.; Chen, W. Fabrication of $\mathrm{CuO} / \mathrm{C}$ films with sisal-like hierarchical microstructures and its application in lithium ion batteries. J. Alloys Compd. 2009, 476, 408-413.

(27) Li, F.; Liu, X.; Zhang, Q.; Kong, T.; Jin, H. Fabrication and photocatalytic property of $\mathrm{CuO}$ nanosheets via a facile solution route. Cryst. Res. Technol. 2012, 47, 1140-1147.

(28) Yamamoto, K.; Kasuga, T.; Nogami, M. Electrochemical Reactions of a Novel Oxygen Sensor Using Copper(I)-Conducting Glass-Ceramics. Electrochem. Solid State Lett. 1999, 2, 595-596.

(29) Gao, X. P.; Bao, J. L.; Pan, G. L.; Zhu, H. Y.; Huang, P. X.; Wu, F.; Song, D. Y. Preparation and electrochemical performance of polycrystalline and single crystalline $\mathrm{CuO}$ nanorods as anode materials for Li ion battery. J. Phys. Chem. B 2004, 108, 5547-5551.

(30) Rao, M. P.; Wu, J. J.; Asiri, A. M.; Anandan, S.; Ashokkumar, M. Photocatalytic properties of hierarchical $\mathrm{CuO}$ nanosheets synthesized by a solution phase method. J. Environ. Sci. 2018, 69, 115-124.

(31) Kosa, S. A.; Maksod, I. H. A. E.; Alkhateeb, L.; Hegazy, E. Z.; Hegazy, E. Z. Preparation and surface characterization of $\mathrm{CuO}$ and Fe2O3 catalyst. App. Surf. Sci. 2012, 258, 7617-7624.

(32) Sankar, R.; Manikandan, P.; Malarvizhi, V.; Fathima, T.; Shivashangari, K. S.; Ravikumar, V. Green synthesis of colloidal copper oxide nanoparticles using Carica-papaya and its application in photocatalytic dye degradation. Spectrochim. Acta, Part A 2014, 121, $746-750$.

(33) Wang, H.; Pan, Q.; Zhao, J.; Yin, G.; Zuo, P. Fabrication of CuO film with network-like architectures through solution-immersion and their application in lithium ion batteries. J. Power Sources 2007, 167, 206-211.

(34) Zhang, Q.; Zhang, K.; Xu, D.; Yang, G.; Huang, H.; Nie, F.; Liu, C.; Yang, S. CuO nanostructures: Synthesis, characterization, growth mechanisms, fundamental properties, and applications. Prog. Mater. Sci. 2014, 60, 208-337.

(35) Yao, Y.; Chen, H.; Qin, J.; Wu, G.; Lian, C.; Zhang, J.; Wang, S. Iron encapsulated in boron and nitrogen codoped carbon nanotubes as synergistic catalysts for Fenton-like reaction. Water Res. 2016, 101, 281-291.

(36) Baskoutas, S.; Terzis, A. F. Size-dependent band gap of colloidal quantum dots. J. Appl. Phys. 2006, 99, 013708-13711.

(37) Rehman, S.; Ullah, R.; Butt, A. M.; Gohar, N. D. Strategies of making $\mathrm{TiO}_{2}$ and $\mathrm{ZnO}$ visible light active. J. Hazard. Mater. 2009, 170, 560-569.

(38) Erdoğan, I. Y.; Güllü, Ö. Optical and structural properties of $\mathrm{CuO}$ nanofilm: Its diode application. J. Alloy. Compd. 2010, 492, 378-383.

(39) Kana, N.; Kaviyarasu, K.; Khamliche, T.; Magdalane, C. M.; Maaza, M. Stability and thermal conductivity of $\mathrm{CuO}$ nanowire for catalytic applications. J. Environ. Chem. Engg. 2019, 7, 103255.

(40) Qasem, M.; El Kurdi, R.; Patra, D. Green synthesis of Curcumin conjugated $\mathrm{CuO}$ nanoparticles for catalytic reduction of Methylene Blue. Chem. Select 2020, 5, 1694-1704.

(41) Uthirakumar, P.; Muthulingam, S.; Khan, R.; Hyeon Yun, J.; Cho, H.-S.; Lee, I.-H. Surfactant-free synthesis of leaf-like hierarchical $\mathrm{CuO}$ nanosheets as a UV light filter. Mater. Lett. 2015, 156, 191-194.

(42) Mukherjee, N.; Show, B.; Maji, S. K.; Madhu, U.; Bhar, S. K.; Mitra, B. C.; Khan, G. G.; Mondal, A. $\mathrm{CuO}$ nano-whiskers: electrodeposition, Raman analysis, photoluminescence study and photocatalytic activity. Mater. Lett. 2011, 65, 3248-3250. 
(43) Xu, H.-Y.; Liu, W.-C.; Qi, S.-Y.; Li, Y.; Zhao, Y.; Li, J.-W. Kinetics and optimization on discoloration of dyeing wastewater by schorlcatalyzed Fenton-like reaction. J. Serb. Chem. Soc. 2014, 79, 361-377.

(44) Wang, Y.; Lü, Y.; Zhan, W.; Xie, Z.; Kuang, Q.; Zheng, L. Synthesis of porous $\mathrm{Cu}_{2} \mathrm{O} / \mathrm{CuO}$ cages using Cu-based metal-organic frameworks as templates and their gas-sensing properties. J. Mater. Chem. A 2015, 3, 12796-12803.

(45) Wu, C.-K.; Yin, M.; O’Brien, S.; Koberstein, J. T. Quantitative analysis of copper oxide nanoparticle composition and structure by $\mathrm{X}$ ray photoelectron spectroscopy. Chem. Mater. 2006, 18, 6054-6058.

(46) Yang, F.; Zhang, X.; Yang, Y.; Hao, S.; Cui, L. Characteristics and supercapacitive performance of nanoporous bamboo leaf-like $\mathrm{CuO}$. Chem. Phys. Lett. 2018, 691, 366-372.

(47) Zhong, K.; Xue, J.; Mao, Y.; Wang, C.; Zhai, T.; Liu, P.; Xia, X.; $\mathrm{Li}, \mathrm{H}$.; Tong, Y. Facile synthesis of $\mathrm{CuO}$ nanorods with abundant adsorbed oxygen concomitant with high surface oxidation states for $\mathrm{CO}$ oxidation. RSC Adv. 2012, 2, 11520-11528.

(48) Liu, S.; Wang, Z.; Wang, F.; Yu, B.; Zhang, T. High surface area mesoporous $\mathrm{CuO}$ : a high-performance electrocatalyst for nonenzymatic glucose biosensing. RSC Adv. 2014, 4, 33327-33331.

(49) Xu, H.; Zhu, G.; Zheng, D.; Xi, C.; Xu, X.; Shen, X. Porous CuO superstructure: Precursor-mediated fabrication, gas sensing and photocatalytic properties. J. Colloid Interface Sci. 2012, 383, 75-81.

(50) Zou, G.; Li, H.; Zhang, D.; Xiong, K.; Dong, C.; Qian, Y. WellAligned arrays of $\mathrm{CuO}$ nanoplatelets. J. Phys. Chem. B 2006, 110, 16321637.

(51) Dörner, L.; Cancellieri, C.; Rheingans, B.; Walter, M.; Kägi, R.; Schmutz, P.; Kovalenko, M. V.; Jeurgens, L. P. H. Cost-effective sol-gel synthesis of porous $\mathrm{CuO}$ nanoparticle aggregates with tunable specific surface area. Sci. Rep. 2019, 9, 11758.

(52) Fuku, X.; Kaviyarasu, K.; Matinise, N.; Maaza, M. Punicalagin green functionalized $\mathrm{Cu} / \mathrm{Cu}_{2} \mathrm{O} / \mathrm{ZnO} / \mathrm{CuO}$ nanocomposite for potential electrochemical transducer and catalyst. Nanoscale Res. Lett. 2016, $11,386$.

(53) Harish, S.; Sabarinathan, R.; Joseph, J.; Phani, K. L. N. Role of pH in the synthesis of 3-aminopropyl trimethoxysilane stabilized colloidal gold/silver and their alloy sols and their application to catalysis. Mater. Chem. Phys. 2011, 127, 203-207.

(54) Azad, U. P.; Ganesan, V.; Pal, M. Catalytic reduction of organic dyes at gold nanoparticles impregnated silica materials: Influence of functional groups and surfactants. J. Nanopart. Res. 2011, 13, 39513959.

(55) Nemanashi, M.; Meijboom, R. Synthesis and characterization of $\mathrm{Cu}, \mathrm{Ag}$ and $\mathrm{Au}$ dendrimer-encapsulated nanoparticles and their application in the reduction of 4-nitrophenol to 4-aminophenol. J. Colloid Interface Sci. 2013, 389, 260-267.

(56) Miyajima, M.; Sagami, I.; Daff, S.; Taiko Migita, C.; Shimizu, T. Azo reduction of Methyl Red by neuronal nitric oxide synthase: The important role of FMN in catalysis. Biochem. Biophys. Res. Commun. 2000, 275, 752-758.

(57) Zhang, D.; Mai, H.; Huang, L.; Shi, L. Pyridine-thermal synthesis and high catalytic activity of $\mathrm{CeO}_{2} / \mathrm{CuO} / \mathrm{CNT}$ nanocomposites. Appl. Surf. Sci. 2010, 256, 6795-6800.

(58) Wang, J.; Fan, X. M.; Wu, D. Z.; Dai, J.; Liu, H.; Liu, H. R.; Zhou, Z. W. Fabrication of $\mathrm{CuO} / \mathrm{T}-\mathrm{ZnOw}$ nanocomposites using photodeposition and their photocatalytic property. Appl. Surf. Sci. 2011, 258, 1797-1805.

(59) Akram, N.; Guo, J.; Ma, W.; Guo, Y.; Hassan, A.; Wang, J. Synergistic catalysis of $\mathrm{Co}(\mathrm{OH})_{2} / \mathrm{CuO}$ for the degradation of organic pollutant under visible light irradiation. Sci. Rep. 2020, 10, 1939.

(60) Bhosale, M. A.; Karekar, S. C.; Bhanage, B. M. Room Temperature Synthesis of Copper Oxide Nanoparticles: Morphological Evaluation and Their Catalytic Applications for Degradation of Dyes and C-N Bond Formation Reaction. ChemistrySelect 2016, 1, 62976307. 